\title{
FROM EXPERT TO EPISTEMIC COMMUNITIES: \\ ON THE TRANSFORMATION OF INSTITUTIONAL FRAMES OF POWER IN THE MODERN WORLD
}

\author{
Marianna Y. Smirnova, Sergey. Y. Yachin \\ assistance lecturer at the Department of Liguistics and Intercultural Communication \\ Far Eastern Federal University, School of Regional and International Studies \\ 690000, Vladivostok, Russky island, campus FEFU, building F, of.732 \\ yachin@land.ru \\ Professor, Head of the Department of Philosophy, \\ Far Eastern Federal University, School of Humanities \\ 690000, Vladivostok, Russky island, campus FEFU, building F, of.732 \\ marianna.y.smirnova@gmail.com
}

\begin{abstract}
The article deals with the phenomenon of epistemic communities. The concept was coined by $\mathrm{P}$. Haas in the late $\mathrm{XX}$ century in an attempt to analyze functions and political prospects of expert and professional knowledge in the modern knowledge-based society. The concept has been widely used during the recent decades in sociology of knowledge, policy studies and social philosophy. Despite the fact that some scholars voiced a number of critical remarks, no (or very few) attempts to rethink the concept of epistemic communities have been made. The article gives a review of research into epistemic communities and introduces the concept of epistemic operating mode in order to rethink the concept and clear up operational mechanisms of epistemic communities as a specific form of knowledge (expert) communities.
\end{abstract}

\section{Indexing terms/Keywords}

epistemic community; expert community; knowledge-based society.

\section{Academic Discipline And Sub-Disciplines}

Philosophy of Science; Sociology of Knowledge

\section{SUBJECT CLASSIFICATION}

Library of Congress Classification (1.2 Class B)

\section{TYPE (METHOD/APPROACH)}

Historical Inquiry; Literary Analysis

\section{Council for Innovative Research}

Peer Review Research Publishing System

Journal: Journal of Social Sciences Research

Vol. 5, No. 1

Jssreditor.cir@gmail.com

www.jssronline.com 


\section{INTRODUCTION}

The concept of epistemic communities was developed by P. Haas in the late XX century to explain how decision-makers and politicians interact with scientific and/or professional communities when challenged with global problems that require expert consulting. E. Haas and E. Adler also significantly contributed to the concept formation.

The concept of epistemic communities suggests that the latter share ideas and resources to promote their ideas (their resources can include political influence or academic reputation). Moreover, any epistemic community combines political initiative with scientific objectivity. This makes epistemic communities different from NGOs, advocacy coalitions, interest groups, etc. The concept has been used widely during the recent decades in sociology of knowledge, policy studies and social philosophy, mainly in various case studies.

The earliest attempts to sum up the research materials date back to the first decade of the XXI century. In 2012, a review article «Rethinking epistemic communities twenty years later» by M. D. Cross was published. The survey of both the lastcentury and latest research papers gives an idea of how the concept has evolved and admits the necessity to reconceptualize it. Cross's innovation is expanding the concept by including non-scientific/non-expert knowledge into the domain of epistemic communities. This is probably the most cover-all article on the matter. Some others, which are touched upon in this article, try to refine the concept in other ways. But these attempts are rather scarce. And some questions are still to be answered - or answered on a renewed theoretical basis. First of all, it is the question of defining epistemic communities' boundaries: how can one differentiate between epistemic and other communities? Another disputable question is whether epistemic communities have easily definable limits of political independence.

The concept of espistemic communities requires re-interpetatitg with regard to the above-mentioned challenges.

The given article suggests the concept of «epistemic operating mode», which is intended to clear up the matter of defining epistemic communities' functional boundaries and eliminates some contradictions, which inevitably emerge when epistemic communities are considered to be a permanent structure, not a mode in which an expert community is functioning under certain conditions.

\section{THE FORMING OF THE EPISTEMIC COMMUNITY CONCEPT}

The concept of epistemic community in its current meaning was formed in the late XX century (the 90 -s) by E. Haas, P. Haas, and E. Adler. However, the idea that knowledge-based communities are of political importance had been developed earlier, in the 70-s and 80-s.

The concept of epistemic community takes its origin in the «episteme» concept. The latter was widely used by M. Foucault. In 1975, J. Ruggie introduced the term «epistemic community» with the reference to Foucault [1].

In the course of time, the concept grew more and more policy-oriented. However, in the 80-s the term «epistemic community» still had various interpretations. E. Haas and P. Haas followed J. H. Marx and B. Holzner who defined epistemic communities as «those knowledge-oriented work communities in which cultural standards and social arrangements interpenetrate around a primary commitment to epistemic criteria in knowable production and application» [2].

E. Haas expanded this definition and included into the list of basic characteristics of epistemic communities adherence to certain shared values and political initiative. In 1989, P. Haas analyzed factors underlying the success of the so-called Mediterranean Plan. He found that it had succeded due to engaging scientists, marine biologists, ecologists (members of an epistemic community) in the agenda-forming [3]

In 1992, Haas gave his own interpretation of the epistemic community concept in the «Introduction: Epistemic communities and International Policy Coordination». Today, it is the most widely-recognized (and widely discussed) definition of epistemic communities [4]. According to it, epistemic communities have four following features:

«1) a shared set of normative and principled beliefs which provide a value-based rationale for the social action of community members;

2) shared causal beliefs, which are derived from their analysis of practices leading or contributing to a central set of problems in their domain and which then serve as the basis for elucidating the multiples linkages between possible policy actions and desired outcomes;

3) shared notions of validity - that is, intersubjective, internally defined criteria for weighting and validating knowledge in the domain of their expertise;

4) a common policy enterprise - that is, a set of common practices associated with a set of problems to which their professional competence is directed, presumably out of the conviction that human welfare will be enhanced as a consequence» [4].

Besides, P. Haas and E. Adler analyzed the role of epistemic communities in establishing a new world regime. Unlike some of their followers, Adler and Haas considered epistemic communities to be a kind of interpretative filter for political choices rather than a new political actor.

Highly illustrative are two works by Haas and Adler, «Banning Chlorofluorocarbons: Epistemic Community Efforts to Protect Stratospheric Ozone» (1992) [5] and «The Emergence of Cooperation: National Epistemic Communities and the 
International Evolution of the Idea of Nuclear Arms Control» (1992) [6]. The first article presents research into activities of a transnational environmental epistemic community. It made a theoretical basis for the Montreal Protocol on Substances that Deplete the Ozone Layer. The second article analyzes how the idea of global nuclear disarmament evolved in the political interaction between the Soviet Union and the USA which resulted in the Treaty on Anti-Ballistic Missile Systems in 1972. (This research was carried further by M. Dover in 2013 in an article on international cooperation between the USA and the Russian Federation in the field of nuclear weapon non-proliferation in the last decade of the $20^{\text {th }}$ century) [7]).

Also, Haas and Adler made a hypothese that epistemic communities are able to help establish a new alternative world regime without hegemons [8]. This theory can come true only under a number of conditions. The scholars made it clear that effectiveness and succes of this alternative global regime depends on the extent in which it is based on shared values of the humanity, not individual states. It is self-evident that this is the highest goal to strive, which, however, cannot be achieved by formal procedures only.

The above-mentioned works resulted in a commomly recognized and shared by numerous scholars interpretation of epistemic community. Haas' vision of the phenomenon formed a basis for further research in the field of politics, social studies etc. Today, scholars strictly follow Haas when defining epistemic communities.

For example, K. Lynch defines epistemic communities as follows: "groups of individuals sharing a particular interest or expertise who are able to exercise a high degree of influence over the shaping of various public policy issues based on a common interest" [9, 94-95]. P. Harris defines them as "specialist communities who often form international networks on a certain issue or type of knowledge" $[10,87]$. In more recent discussions of epistemic communities Antoniades gives them the following definition: "socially recognized knowledge-based networks, the members of which share a common understanding of a particular problem/issue or a common worldview and seek to translate their beliefs into dominant social discourse and social practice" [11,26], whereas K. Suzuki states that «members of an epistemic community distinctively act on a value-based rationale, shared methods and criteria of analyzing, validating and linking problems and desired outcomes, and have common practices in their exercise of competence" $[12,17]$. Undoubtedly, the scholars use Haas' ideas as a basis for their vision of the phenomenon.

Although the concept has made its way into policy and social studies, it is not widely represented in theoretical, conceptual works. It is used in case studies, predominantly in such fields of research as health (Z. Heritage, J. Green, J. McGivern), environment protection (S. Murphy, K. Rosendal), economics (W. Drake, E. Karayannis), intellectual property (L. Dobush, S. Quak), etc. Works on Asia-Pacific are focused on regional security and economic development (J. Dosch, M. Mols, C. Dent, J. Rueland, M. Schreus, etc.).

Here is a brief overview of the recent research into epistemic communities.

Z. Heritage and J. Green analyze activities of a transnational health epistemic community. According to the scholars, the community significantly contributed into the building of the European national networks «Health City» in 2003-2008 [13]. S. Sturdy, R. Freeman and J. Smith-Merry cover a wider chronological scope by studying activities of the World Health Organization from the 70-s to today [14]. The concept of epistemic communities made a theoretical basis for an article by A. Balch's on migration policy of Great Britain in the first decade of the XXI century [15].

Informal links among epistemic comnmunities' members contribute into consensus-building among decision-makers. Not only do they provide expert knowledge, but also act as an intermediary. R. Tiller, T. Brekken, J. Baily highlight the intermediary function when analyzing political processes in integrated management of coastal aquacultures in Norway. Despite the fact that epistemic communities are underdeveloped there, the scholars hope that their emergence could prevent conflicts in this field [16]. However, it is difficult to measure how influential epistemic communities can be. D. J. Galbreath and J. McEvoy were challenged with this problem when trying to clear up the role of epistemic communities in the EU policy concerning minorities [17].

L. Dobush and S. Quack analyze the case of «Creative Commons», a non-profit organization which addresses intellectual property issues [18]. They regard it as a politically successful epistemic community of lawyers. But their success is accounted to activities going far beyond the limits of an epistemic community. In fact, the «Creative Commons» acted as a social movement because interpretative functions of epistemic communities were obviously insufficient. I. Rossi considers the community of Linux developers to be epistemic, too [19]. This community is a community of software developers, active professionally and politically. Lust like "Creative Commons», they use a wider range of instruments than epistemic communities as they were described by Haas. The tendency to reformulate the concept may be explained by the scholars' doubt in political efficiency of pure expert knowledge.

It is to note that there are very few attempts to theoretically expand or rethink the concept. Among them are ideas of $\mathrm{K}$. Bukhari, who, in search for theoretical foundations, pointed out that constructivism, with its vision of scientific knowledge as a socially constructed phenomenon, perfectly correlating with the epistemic community concept [20]. K. Dunlop proposes another interesting approach to epistemic communities. She lists epistemic communities as one of the key paradigms used to analyze political learning. Epistemic learning, i. e. learning through epistemic actors, experts, suggests that epistemic communities act as tutors of a kind. However, it is their "students" - decision-makers - that direct the process of learning by selecting prioritized knowledge fields and issues to debate [21].

Probably, the most remarkable theoretical all-emrbacing work is the above-mentioned article by M. D. Cross «Rethinking epistemic communities twenty years later». According to Cross, the concept requires further conceptual development. Her own idea is that international epistemic communities should not be limited to scientific ones, that is, their knowledge should not be limited to scientific data [22]. M. Meyer and S. Molyneux-Hogson also reviewed and summed up existing variants of 
the concept. As many before them, they pointed out that they do not fully explain how epistemic communities form and function [23].

It is to be concluded that epistemic communities are currently under research, but most of the scholars follow Haas' definition and highlight two crucial features of epistemic communities: their political potential and shared knowledge and values of their members. The vast majority of works dedicated to epistemic communities are case studies which provide diverse examples but do not rethink or reinterpretate the concept itself, with some rare exceptions. However, the concept of epistemic comminities needs refining (if not redefining).

\section{KNOWLEDGE AS SOCIAL POWER OR DISCOURSE OF POWER}

Knowledge is of special importance in a society faced with high uncertainty and unpredictable risks in decision-making. The modern knowledge-based society combines high technological and environmental risks with a knowledge basis comprised of unprecedentedly diverse scientific data - ironically, science both generates risks and is required to eliminate them. This dualism has been pointed out by G. Bechmann, according to whom, the contemporary society is differentiated from the previous stages of social development by its ways of addressing global uncertainty. The society does it by regarding its own future as a kind of risk. In fact, risk is the necessity to make decisions in the context of high uncertainty [24].

In the broad context of information society studies it is important to take into account the role of goal-setting subjects of knowledge (groups and individuals) in this society. The phenomenon of epistemic communities is interlinked with the process when scientists do not just serve the interests of economic and political actors but also try to solve global problems. Under these conditions, scientists do not just seek new knowlege and, consequently, the truth, which is the essence of scientific cognition. While considering the truth to be the highest value, they are also able to use their shared vision of the truth (knowledge) to address global political and economic issues.

The Pugwash Movement, which was founded in 1955 by a group prominent scientist, can serve as an example of such community. The Movement positions itself as a community of technical experts engaged in policy-oriented studies in the field of international security and arms control.

In the modern knowledge-based society it is crucial for scientists to understand which criteria can be used to justify their theories, because their object of cognition are not natural objects but technical/sociotechnical objects and developments.

Importantly and predictably, an emerging «knowledge economy» (or «innovative economy») results in increasing influence of scientists - bearers of domain-specific, predominantly scientific knowledge. The influence manifests itself in all social spheres: politics, culture, everyday life. As a rule, these recommendations are collective. In other words, they express a shared epistemic (knowledge-based) position of a certain scientific community.

The tendency to rely upon integrated expert knowledge for (predominantly) political and economic decision-making is a kind of modern innovation in itself. First of all, this tendency means that it $s$ possible to integrate knowledge of various specialists (scientists) and obtain new knowledge which is shared by all scientists but does not belong to any scientist as an individual. That is why it is necessary to differentiate the competence of a individual expert, which is as old as human civilization, from the competence of an expert group, a community of specialists capable of proposing collective solutions.

Special methods are required to obtain such shared knowledge. A popular method of polling scientist has been known since the $60^{\text {th }}$ of the XX century under the name «Delphi method». There is no reason to apply expert polls in highly specialized fields of knowledge which require experimental proof. Knowledge integration becomes useful when knowledge is a «direct productive force» and, when practically applied, leads to significant economic, political and social changes.

That is why knowledge integration and expert evaluation are usually required at the conceptual (empirically non-verifiable) level and to forecast development of technical systems, weapons, climate changes, social institutions, on one hand, and deveop scenarios of multi-level social subjects' actions, on the other.

Epistemic communities emerge to meet the challenge of global uncertainty. The reasons for involving epistemic communities into policy-making were roughly analyzed by $\mathrm{P}$. Haas, who wrote that decision makers turn to epistemic communities for them to make a forecast, predict possible outcomes of a certain political course, help form it [4].

Strictly speaking, these are rather expectations than reasons. Politicians seek expert help in decision-making, but why do politicians believe that experts are able to help them? It is not only because they need information due to high uncertainty. It is also because scientific and expert knowledge are expected to have some ethical basis and be oriented at the global common good, human welfare. Or, at the very least, policy-makers use the concept of ethically concerned scientific knowledge to legitimize their actions. Even so, ethical foundations of knowedge usage are typical of this concept of science. Expert - and epistemic - communities are regarded as a linkage between policy anf science. As such, they have some specific power.

The idea of viewing epistemic communities as bearers of specific power first emerged in the works by M. Foucault in the context of his concept of discourse power [25]. In the frame of this concept power is regarded as a kind of discourse and an instinctive social power. This power does not belong to anyone, being an integrative factor for social groups, but it can be consolidated in the hands of an individual or some institution. Foucault revealed the mechanism of aquiring social power through the order of discourse (through the right to legitimize differences). 
Although Foucault did not analyze the phenomenon of epistemic communities in itself, it is impossible to understand the principles of their forming without understanding the idea of discourse power. It is neither knowledge itself that has power, nor an individual who owns this knowledge. It is the discursive order which this knowledge (and individuals who own it) can make legitimate. The knowledge which has power is a kind of knowledge expressed in the text of an instruction or a decree, in a state program, a financial code and directly in legislation. In the modern world fight for power is predominantly a fight for the way of describing (discourse) of human and social reality.

In the frame of this approach, science is regarded as a kind of discourse, along with the discourse of religion, art, journalistics, etc.. A full range of consequences of science transformation into a kind of dicourse is presented in a widely recognized work by J.-F. Lyotard «The Postmodern Condition: A Report on Knowledge» [26]. Of great importance is the implication that knowledge cannot gain power if it skips the stage of becoming the language of a certain community: at first - scientists, later - well-educated people, at last - politicians or decision-makers. After twenty five years the concept of discourse power becomes a theoretical foundation and ideological justification of the so-called «soft power» policy (see J. Nye for «soft power») [27].

The phenomenon of epistemic communities is interlinked with the process when scientists do not just serve the interests of economic and political actors but also try to solve global problems. Under these conditions, scientists do not just seek new knowlege and, consequently, the truth, which is the essence of scientific cognition. While considering truth to be the highest value, they are also able to use their shared vision of the truth (knowledge) to address global political and economic issues.

Epistemic communities are also expected to provide communicative environment for science, society and political processes. Globalization - in addition to scientific progress - makes risks increasingly high, due to which expert knowledge becomes unprecedentedly valuable. At the same time, globalization creates a special informational environment which is perfect for knowledge dissemination. At the same time, globalization sets a limit on governments' ability to cope with economical, financial, environmental processes which affect the humanity across territorial borders. No state can successfully cope on its own with international crime, epidemics or climate changes. Epistemic communities act as agents of globalization by providing a platform for multi-lateral dialogues of various actors: governments, enterprises, NGOs, etc. [28].

The necessity to forecast consequences of certain decisions, develope alternative scenarios and help form a consensual position of all participants of any multilateral project is typical of innovative knowledge-based economy. We believe that the epistemic discourse correlates with the prognostic function of scientific cognition. Since epistemic communities are to meet this challenge, their major activity is foresight. Foresight proceeds from an assumption that the desired future can be made true by coordinated efforts only. Literally, foresight does not answer the question: "What will happen?". It answers the question: "What should be done for something to happen?". Foresight is used to influence upon future, to form it, not just to predict it. Prognosis is just a component of foresight [29]. This accounts for a significant specific feature of foresight (and epistemic communities): tendency to involve decision-makers at all stages of development.

\section{POLITICAL INDEPENDENCE OF EPISTEMIC COMMUNITIES: CRITICS AND DEBATES}

The concept of epistemic communities, despite its wide usage, provokes critics when applied to international policy coordination as its only explanation.

As early as $1992 \mathrm{~J}$. Sebenius made some critical remarks to Haas' works by pointing out that mechanisms of transforming values and ideas into political power were not properly explained [30]. Nearly a decade later A. Mooney and B. Evans voiced similar critics. They doubted that epistemic communities always have access to political agenda [31]. Epistemic communities cannot exist without direct links to politicians, and P. Haas underlined this fact: epistemic communities are neither scientific nor political groups. That is why some scholars, for example, J. Peel, claim that institutionalization of epistemic communities is vitally important for their efficiency [32]

Of course, it is commonly accepted that the process of institutionalization can transform an epistemic community into some kind of interest group or avocacy coalition which acts to benefit governments or corporations. In this case no independence is possible. Some scholars are much more optimistic, however. For example, M. Sundstroem suggests that international epistemic communities can influence national experts so effectively that the latter develop a shared vision of current global problems at the national level and tend to arrive at an international agreement easier [33]

Of much interest is D. Toke's critics of the epistemic community concept. He «accused» Haas of underestimating influence of interest groups [34]. K. Litfin and G. Kuetting provided some critics, too. Liftin analyzed the process of the Montreal Protocole in 1987 and admitted that scientists played an important role in developing political agreement. However, she pointed out that the epistemic communities approach simply underestimated how often scientific data were used just for the legitimization of current policy courses [35]. G. Kuetting claimed Haas' statement that epistemic communities played the decisive role in forming the Mediterranean Plan has no foundations [36].

The above-described critics make one think about how epistemic communities (knowledge) interact with decision makers (power) in general. Scholars have not arrived at an agreement in this question yet. Their opinions range from very optimistic to highly pessimistic, which is due to the fact that the researchers judge by the result of their case studies, too narrow and specific to cover a wider area. 
Thus, J. McGivern presented an example of an effective epistemic community without actual governmental support: the multidisciplinary biomedicine network «University Genetics Knowledge Park» made to transfer scientific data into the British health system. McGivern tracked key stages of this process and described interaction between the epistemic community and other actors. Strictly speaking, the network was initiated by the government. But the latter failed to control it and cut the financing. In spite of this, the data provided by the experts found its way into the health system [37]. On the contrary, K. Dunlop described a totally different case by comparing two scientific groups which worked in he EU as two types of epistemic community. The groups addressed the issue of the growth hormone. One was government-initiated, the other formed evolutionally. Dunlop came to a conclusion that decision makers cannot delegate their power to an independent epistemic community, so they tend to establish their own communities by recruiting experts [38]. This conclusion undermines the idea of an independent and yet influential epistemic community. This is no exception. Sometimes scholars, such as M. King, regard epistemic communities' success as a result of mere coincidence of their goals with the goals of decision-makers [39]. However, some researchers (for example, the above-mentioned Heritage and Green) regard governmentally initiated epistemic communities as quite normal and effective.

We think that this dispute can be productive in the context of individual case studies only. Contemporary political practices provide so controversial data on epistemic communities' efficiency that no generalistic approach is suitable.

\section{DEFINING BOUNDARIES OF EPISTEMIC COMMUNITIES: FROM EXPERT TO EPISTEMIC COMMUNITIES}

The problem of defining boundaries of epistemic communities is especially difficult. They do not have a strict structure and, just like an «invisible college», can include members of various organizations: scientists, researchers, politicians, governmental officials, etc. However, no epistemic community can be fully integrated into governmental structures or corporations. Within an epistemic community only horizontal links can be effective, due to its network-like structure. In other words, any epistemic community, with its interdisciplinairy and absence of a formal leader, can be described as a network with a number of local "centers". It makes them different from other forms of knowledge organization, such as laboratories, think collectives, etc.

Epistemic communities should be distinguished from bureaucracy and interest groups. Interest groups usually promote views of a certain coalition. It is not their values and beliefs that urge their members to intervene with policy-making processes. Thus, an epistemic community can include scientists, researchers, interest group analysts and public officials, often operating in a private capacity, but it is more than just a scientific, political or interest group. Also, disputable is the question whether non-governmental organizations belong to epistemic communities.

$P$. Haas was the first to try to differentiate between epistemic communities and other groups of the kind. He made up two schemes to illustrate the differences using two differentiating criteria: 1) shared causal beliefs; 2) knowledge basis of a certain type. Later, epistemic communities have been compared to various structures: policy communities or policy transfer networks (M. Evans, J. Davis), NGOs (J. Braithwaite, P. Drahos, K. Gough), discourse coalitions (K. Litfin). It is quite obvious that all these groups and communities can be compared to epistemic ones from the standpoint of their functional and structural characteristics. But they do not form the basis for epistemic communities. Expert groups do - to some extent.

Epistemic communities can be viewed as a specific form of scientific community, because any cognitive activity is collective (meaning "live" knowledge exchange). The forming of increasingly broader scientific communities can be traced back to antiquity, when these communities were limited to scientific schools [40]. Later, professional communities (and universities) emerged. Expert communities emerged no earlier than in the $X X^{\text {th }}$ century. It is not the final stage, though. Today expert communities can only be understood in the context of the forming of broader communities - epistemic ones. This historical sequence can be imagined as building one integration level over another. Expert communities are based on professional ones, professional communities stem from scientific schools.

Expert knowledge differs from classical scientific knowledge by its structure. It is required to use integrated expert knowedge to solve strategic economic and political problems. However, a paradox emerges: knowledge of physics, psycology, economics, etc. as separated fields od expertise looses its social (innovative) importance. Scientific knowledge becomes a political and economic power only in its systems, integrated and, to a great extent, interdisciplinary form. Expert knowledge is differentiated from scientific knowledge by its subject. While the latter studies real objects, expert knowledge deals with tendencies and foresight, in other words, non-existing or virtual objects. Therefore, expert knowledge is predominantly applicable to future scenarios developing (foresight).

The different ways of functioning of scientific and expert knowledge are the key to understanding the forming factors of expert communities, decision-making processes and politically or economically relevant recommendations, as well as to understanding the reason why any major organization - an industrial corporation, public authorities or international organizations like APEC - have to rely upon trust expert evaluations and form expert groups.

The crucial difference between epistemic communities and expert groups is that the latter play a passive instrumental role. They are bearers of tacit knowledge which can be revealed by a special method - expert polls. Delphi method suggests that experts are independent from each other, or (which is better) do not know each other at all. On the contrary, an epistemic position of an expert is personal and value-based.

Today, we have an opportunity to deeper understand the role of expert communities - mostly due to the fact that we can view them from the standpoint of a relatively new phenomenon of self-organized expert groups which can be subjects of their knowledge, or, in other words, apply their knowledge to political and economic decision-making. Such self-organized 
expert communities are capable of promoting this or that economic/political decision based on their shared vision of the true and the right. This means they are epistemic by their shared values.

Epistemic communities can be based on expert ones, being a higher level of their development to the extent in which they take human well-being into account. However, one cannot say that an expert community ends where an epistemic one begins. It is not a direct, historically retraceble sequence. The main reason for that is that any epistemic community is not an institution. It is a process of a kind, a state of mind which is enabled but a number of factors including human factor. An expert community can act as an epistemic one, which means, it is an epistemic community under current conditions.

\section{EPISTEMIC OPERATING MODE}

Epistemic communities do not have strictly defined boundaries. On one hand, thay can be regarded as a higher level of expert knowledge integration and development (compared to expert communities). But an epistemic community does not remain active forever. A. Antoniades reasonably divided epistemic communities into two categories: ad-hoc coalitions and permanent coalitions [11]. Ad-hoc coalitions are established to solve a certain political problem. Permanent global groups are aimed at promoting their ideas and beliefs as the dominant social discourse.

However, this distinction seems to be irrelevant when it comes to the major defining feature of epistemic communities: they believe that addressing global issues is an urgent necessity. In our understanding, which is rather close to the initial concept developed by Haas, a community is epistemic when it meets this criterion and, as a result, has some political initiative. No community can comply with this requirement at all times, so we propose the following idea. Any international expert (scientific) community can operate in different modes: as an interdisciplinary scientific community united by a common problem to solve; as an expert community given a task by some institution or government; as an epistemic community promoting its shared knowledge to help solve global problems.

That is why research should be done into ways of epistemic communities' functioning, their operating mode. In this paper, it is suggested to regard any knowledge-based community from the standpoint of its specific operating mode which can be defined as epistemic operating mode.

Epistemic mode can be estimated with the help of characteristics given below.

1) Self-organization. Members of an «ideal» epistemic community act on their own initiative and cannot be recruited by governments or corporations to make their policy legitimate. However, grants or contracts do not make epistemic mode wholly impossible. Expert groups of international organizations or members of international projects can swith to the epistemic mode, being partly self-organizing.

2) Scientific truth as a shared value. No personal interest can be taken into account. Search for political compromise does not necessarily deny search for the truth. But it remarkably changes the operating mode of a community.

3) Personal position of any expert member of the community, which basically means that experts willingly take personal responsibility for their recommendations.

4) Adherence to shared values. A community working in the epistemic mode has a common system of values. On the contrary, a distinctly neutral (ethically) position of experts indicates that their community is not epistemic.

5) Political influence. Epistemic mode requires significant political influence which can be ensured by engaging decisionmakers (politicians, investors).

5) Interdisciplinarity. In many cases, it ensures that projects under discussion can be realized. Therefore, high level of interdisciplinarity indicated epistemic mode. Strictly theoretical problems limited by a single discipline makes operating in this mode impossible.

6) Focus on global problems which affect human development, well-being, security. Such activities as foresight, scenarios of possible future variants are indicative. Epistemic communities seldom focus on solving problems which do not have any long-term consequences. When most of these features are undoubtedly seen in the activity of a certain international scientific community, this community can be regarded as epistemic - which means, acting in the epistemic mode.

\section{CONCLUSION}

It is to note that any knowledge-based community can be characterized with the help of these criteria. They allow to define when and under what conditions it functioned in the epistemic mode. This approach explains many противоречия оf existing concepts. They can also be used in developing measures to initiate epistemically functioning communities or switch existing expert groups into this mode.

\section{ACKNOWLEDGEMENTS}

This paper was supported by a grant of Far Eastern Federal University \#12-05-06-680-09/13

\section{REFERENCES}

[1] Ruggie, J. 1998. Constructing the world polity: Essays on international institutionalization. Routledge.

[2] J. H. Marx, J. H., Holzner, B. 1979. Knowledge application: the knowledge system in society. Allyn and Bacon. 
[3] Haas, P. M. 1989. Do Regimes Matter? Epistemic Communities and Mediterranean Pollution Control. In International Organization. Knowledge, Power, and International Policy Coordination 3/43, 377-403.

[4] Haas, P. M. 1992. Introduction: Epistemic Communities and International Policy Coordination. In International Organization. Knowledge, Power, and International Policy Coordination 1/46, 1-35.

[5] Adler, E., Haas, P. M. 1992. Banning Chlorofluorocarbons: Epistemic Community Efforts to Protect Stratospheric Ozone. In International Organization. Knowledge, Power, and International Policy Coordination 1/46, 187-224.

[6] Adler, E., Haas, P. M. 1992. The Emergence of Cooperation: National Epistemic Communities and the International Evolution of the Idea of Nuclear Arms Control. In International Organization. Knowledge, Power, and International Policy Coordination 1/46, 101-145.

[7] Dover, M. 2013. Hard Problems, Soft Answers: Impact of Epistemic Communities on U.S.-Russian Nuclear Cooperation. Dissertation. American University.

[8] Adler, E., Haas, P. M. 1992. Conclusion: Epistemic Communities, World Order, and the Creation of a Reflective Research Program. In International Organization. Knowledge, Power, and International Policy Coordination 1/46, 367390.

[9] Lynch, K. L. 2003. The forces of economic globalization: Challenges to The Regime of International Commercial Arbitration. Kluewer Law International.

[10] Harris, P. 2004. Global Warming and East Asia: The Domestic and International Politics of Climate Change. Routledge.

[11] Antoniades, A. 2006. Epistemic communities, epistemes and the construction of (world) politics. In Global Society 1/17, 21-38.

[12] Suzuki, K. 2003. Policy logic and institutions of European space collaboration. Ashgate Publishing, Ltd., Aldershot.

[13] Heritage, Z., Green, G. 2013. European National Healthy City Networks: The Impact of an Elite Epistemic Community. In Journal of Urban Health 1/90, 154-166.

[14] Sturdy, S., Freeman, R., Smith-Merry, J. Making Knowledge for International Policy: WHO Europe and Mental Health Policy, 1970-2008. In Social History of Medicine 3/26, 532-544.

[15] Balch, A. 2009/ Labour and Epistemic Communities: The Case of 'Managed Migration' in the UK. In The British Journal of Politics \& International Relations 4/11, 613-633.

[16] Tiller, R., Brekken, T., Bailey, J. Norwegian aquaculture expansion and Integrated Coastal Zone Management (ICZM): Simmering conflicts and competing claims. In Marine Policy 5/36, 1086-1095.

[17] Galbreath, D. J., McEvoy, J. 2013. How epistemic communities drive international regimes: The case of minority rights in Europe. In Journal of European Integration 35/2, 169-186.

[18] Dobusch, L., Quack, S. (ed). 2010. Epistemic Communities and Social Movements: Transnational Dynamics in the Case of Creative Commons. In Transnational Communities: Shaping Global Economic Governance, $226-252$. Cambridge University Press.

[19] Rossi. I. 2007. Frontiers of globalization research: Theoretical and methodological approaches. シュプリンガー・ジャ パン株式会社.

[20] Bukhari, K. Constructivism and epistemic community: theoretical tools for understanding the crafting of foreign policy toward non-state actors. In The McMaster Journal of Communication 1/1, 34-46.

[21] Dunlop, C. 2013. Systematizing Policy Learning: From Monolith to Dimensions. In Political Studies 3/61, 599-619.

[22] Cross, D. M. 2012. Rethinking epistemic communities twenty years later. In Review of International Studies 1/39, 137160.

[23] Meyer, M., Molyneux-Hogson, S. 2010. Introduction: The dynamics of epistemic communities. In Sociological Research Online 2/15. URL: http://www.socresonline.org.uk/15/2/14.html

[24] Бехманн, Г. 2010. Современное общество: общество риска, информационное общество, общество знаний. Логос.

[25] Foucault, M. 1971. L'Ordre du discurs. Gallimard.

[26] Lyotard, J.-F. 1984. The Postmodern Condition. Manchester University Press.

[27] Nye, J. 2005. Soft Power: The Means to Success in World Politics.Public Affairs.

[28] Braithwaite, J, Drahos, P. 2000. Global business regulations. Cambridge University Press.

[29] Bishop P., Hines A. 2006. Thinking about the Future: Guidelines for Strategic Foresight. Washington DC: Social Technologies. 
[30] Sebenius, J. 1992. Challenging conventional explanations of international cooperation: Negotiation analysis and the case of epistemic communities. In International Organization. Knowledge, Power, and International Policy Coordination $1 / 46,323-365$.

[31] Mooney, A., Evans, B. 2007. Globalization: the key concepts. Taylor and Francis.

[32] Peel, J. 2010. Science and Risk Regulation in International Law. Cambridge University Press.

[33] Sundstroem, M. 2000. A Brief Introduction: What is an Epistemic Community? URL: www.svet.lu.se/joluschema/epistcomm.pdf

[34] Toke, D. 1999. Epistemic communities and environmental groups. In Politics 19/2, 97-102.

[35] Litfin, K. 1994. Ozone Discourses: Science and Politics in Global Environmental Cooperation. Columbia University Press.

[36] Kuetting, G. 2000. Environment, Society and International Relations: Towards More Effective International Agreements. Routledge, 2000.

[37] McGivern, G. 2010. Inter-epistemic Power and Transforming Knowledge Objects in a Biomedical Network. In Organization Studies 12/46, 1667-1686.

[38] Dunlop, C. 2010. Epistemic communities, relational distance and the two goals of delegation: Hormone growth promoters in the European Union. In Science and Public Policy 3/37, 205-217.

[39] King, M. 2005. Epistemic Communities and the Diffusion of Ideas: Central Bank Reform in the United Kingdom. In West European Politics 1/28, 94-123.

[40] Collins, R. 1998. The Sociology of Philosophies. A Global Theory of Intellectual Change. Cambridge, Massachusetts: Cambridge University Press.

\section{Author' biography with Photo}

M. Smirnova

M. Smirnova is an assistance lecturer at the Department of Liguistics and Intercultural Communication at the Far Eastern Federal University, School of Regional and International Studies, and a post-graduate student majoring in social philosophy. Her areas of research interest are methodology of social cognition and social processes in the knowledgebased society.

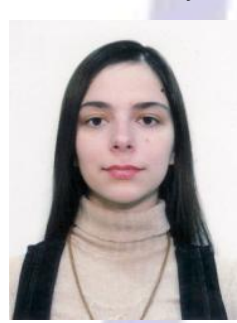

Dr. S. Yachin

Professor S. Yachin, Ph. D., obtained the degree in Philosophy in 1975 and is currently the Head of the Department of Philosophy at the Far Eastern Federal University, School of Humanities. His areas of research interest are methodology of social cognition and philosophical anthropology. S. Yachin is the author of more than 70 works incuding monographs and has been the head of a number of government-funded federal research projects in 2008-2013.

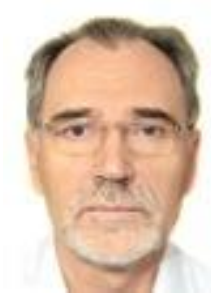

